\title{
General Psychiatry Biological mechanism study of meditation and its application in mental disorders
}

\author{
Hui Shen, ${ }^{1}$ Meijuan Chen, ${ }^{1}$ Donghong Cui ${ }^{1,2}$
}

To cite: Shen H, Chen M, Cui D. Biological mechanism study of meditation and its application in mental disorders. General Psychiatry 2020;33:e100214. doi:10.1136/ gpsych-2020-100214

Received 26 February 2020

Revised 08 May 2020

Accepted 09 June 2020
Check for updates

(C) Author(s) (or their employer(s)) 2020. Re-use permitted under CC BY-NC. No commercial re-use. See rights and permissions. Published by BMJ.

${ }^{1}$ Shanghai Mental Health Center, Shanghai Jiao Tong University School of Medicine, Shanghai, China

${ }^{2}$ Shanghai Key Laboratory of Psychotic Disorders, Shanghai, China

Correspondence to Dr Donghong Cui; manyucc@126.com

\section{ABSTRACT}

In recent years, research on meditation as an important alternative therapy has developed rapidly and been widely applied in clinical medicine. Mechanism studies of meditation have also developed progressively, showing that meditation has great impact on brain structure and function, and epigenetic and telomere regulation. In line with this, the application of meditation has gradually been expanded to mental illness, most often applied for major depressive disorders and substance-related and addictive disorders. The focus of this paper is to illustrate the biological mechanisms of meditation and its application in mental disorders.

Over the centuries, meditation has been practised in different forms and in various cultures. Modern meditation techniques detached from religion are widely used in psychological and clinical medicine. At present, there is no unified definition of meditation, instead it can be classified into focused attention meditation (FA), open monitoring meditation (OM), transcendental meditation (TM), loving-kindness meditation (LKM), mindfulness meditation (MM) and body-mind meditation (B-M). FA and $\mathrm{OM}$ are traditional meditations derived from Zen, Vipassana and Tibetan Buddhism. The practice of FA entails the sustained and selective attention on a chosen object, of which respiration is common, so that the wandering mind is brought back to the selected object of attention, that is, 'just a thought prevailing over thoughts'. ${ }^{1}$ OM only maintains the state of insight and awareness, paying attention to anything (thoughts, feelings, emotions and so on), without judging and evaluating these thoughts. ${ }^{2} \mathrm{MM}$ is the most extensively used in meditation techniques with an integrated FA-OM essence. The techniques which form the primary basis of mindfulness-based interventions (MBIs) are commonly implemented, including mindfulness-based stress reduction (MBSR), mindfulness-based cognitive therapy (MBCT), dialectical behaviour therapy, acceptance and commitment therapy (ACT) ${ }^{3}$ and mindfulness-based relapse prevention (MBRP). Tai chi, qi gong and yoga, which promote mental concentration, relief of pain and modulation of emotions, are currently popular meditation techniques belonging to the B-M method that combines exercise and FA as well as OM methods. Among these, tai chi represents the crystallisation of the collective wisdom in the Chinese cultural heritage and incorporates the basic theories of traditional Chinese medicine. ${ }^{4}$ Nowadays, MBIs and B-M techniques are most commonly applied in mental disorders.

However, TM and LKM have not been widely applied for psychiatric disorders. TM practitioners from India or China ${ }^{5}$ attempt to prevent distraction and reach deep physical and mental relaxation by repeating a mantra (uttered silently). This meditation technique has been applied in patients with post-traumatic stress disorder (PTSD). There is also a special type of Buddhist meditation designed to cultivate an unconditional kindness towards yourself and others, called $\mathrm{LKM}^{6}$ which has been implemented in both depression and schizophrenia.

In this review, we will explore the biological mechanisms underlying meditation and introduce the application of various types of meditation in mental disorders.

\section{BIOLOGICAL MECHANISMS OF MEDITATION}

In recent years, biological mechanisms of meditation have been investigated step by step. Studies demonstrate that various kinds of meditation can change brain structure, adjust brain function, reconstruct brain networks and preserve the homeostasis of the autonomic nervous system (ANS). These fields about modulating epigenetics and improving telomere regulation are still in their infancy, with research focusing primarily on MM. 


\section{Insight on meditation and its brain mechanisms}

Over the years, studies of the mechanism of meditation have received widespread attention. Meta-analysis ${ }^{7}$ demonstrated that practising meditation can induce continuous changes of brain structure in eight regions: including frontal cortex related to metacognition, sensory cortex and insula connected with body consciousness, hippocampus linked to memory process, the anterior and medial cingulate cortex as well as orbitofrontal cortex relevant to self-awareness and emotion regulation and the upper longitudinal bundle and corpus callosum involved in cerebral intrahemisphere and interhemisphere communication. Recent studies have further confirmed that meditation increases the hippocampal volume ${ }^{8}$ and enhances the cortical thickness of the prefrontal, insula and anterior cingulate cortex. ${ }^{9}{ }^{10}$ In short, meditation practice can change brain morphology with higher cortex thickness, grey matter volume and density.

Similarly, meditation training can improve function in many brain areas. Meta-analysis ${ }^{11}$ elucidates that three regions of the brain in the caudate nucleus, the parahippocampus and the medial prefrontal cortex are activated when meditation practice was carried out. The caudate nucleus and putamen participate in attention and shield irrelevant information, which enable a meditative state to be realised and maintained; the parahippocampus prevents distraction; the medial prefrontal cortex enhances self-awareness during meditation. These activated areas may represent the core cortical network of meditation states. Moreover, there exists a dynamic process for brain activation by meditation. At the beginning of meditation, the bilateral subfrontal and temporal regions are obviously activated. As the meditation process goes deeper, the activation becomes weak by degrees, with activation concentrating just on the right subfrontal cortex/right insula and the meso/epithelial layer of right temporal lobe in the end. ${ }^{12}$ It can be seen that the meditator experiences an initially intense self-control neural process to calm the brain and the reduction of neuron activity as the depth of meditation in silence increases.

However, the influence of meditation is limited to certain brain regions and to extensive brain networks connections. LKM can not only increase cortical thickness, but also improve the brain function which is seen in multiple areas of the bilateral prefrontal and insula, which are involved in the social emotion networks in meditation practice. ${ }^{9}$ The functional connectivity between the medial prefrontal cortex and bilateral insula/putamen is evidently strengthened during Sahaja yoga meditation, which is crucial for sensory, mood and attention regulation in the brain. In addition, the depth of meditation is closely associated with the medial frontal-insula-striatum network. ${ }^{10} \mathrm{FA}^{13}$ can promote positive changes in the key neural signals (frontal theta inter-trial coherence and parietal P3b latency) of attention networks. Furthermore, meditation also attenuates activity of the default mode network (DMN) ${ }^{14}$ with dysfunction of the DMN subsystem in the anterior (medial prefrontal cortex) and posterior (cingulate cortex) following a larger number of long-term meditations. ${ }^{15}{ }^{16}$ Our study ${ }^{17}$ observed reduced DMN activity in monks following persistent meditation practice and reconstruction of the large-scale network of EEG gamma waves as well as theta waves by meditation.

In summary, the mechanisms underlying the effects of meditation on the brain may be far more complicated than what we found, which is more relevant to alterations in large-scale brain networks. Future research on brain mechanisms should emphasise complex network analysis.

\section{Insight on meditation and its ANS}

Prolonged meditation can enhance autonomic nerve function, increase parasympathetic nerve activity and decline sympathetic innervation. Heart rate (HR) and heart rate variability (HRV) are frequently used as biomarkers of ANS activity, especially high-frequency HRV. As is known, high-frequency HRV is an index of parasympathetic nervous system (PNS) activity, and it is correlated with attention, working memory and emotion regulation. ${ }^{18}$ In contrast, HR, as an index of sympathetic nervous system (SNS) activity, is related to cognition arousal and subjective efforts. ${ }^{19}$ As meditation time goes on, the subjective effort perceived by meditators will decrease, and then HR will decrease, while the high frequency HRV will increase. However, different meditation methods seem to have distinct influences on the ANS. ${ }^{20}$ Meditations concerning positive psychological intentions, such as LKM and monitoring meditation can activate SNS and enhance alertness; FA can activate PNS to help practitioners reach relaxation. Our previous study explored the effects of traditional Tibetan Buddhist meditation on brain-heart interaction. The results demonstrated that meditation was linked to cardiac function through the coupling of neural viscera and the spontaneous massive spatiotemporal brain network activity and mediated the stability of ANS function. The immediate effect of meditation on heart regulation is connected with the reconstruction of the $\gamma$-wave brain network, and prolonged regulation of meditation for cardiac rhythm is related to the reconstruction of the $\theta$-wave brain network. ${ }^{17}$ In conclusion, our ability to preserve the homeostasis of the ANS will increasingly improve as we practice meditation more.

\section{Insight on meditation and its inflammatory cytokines}

Cytokines are regulators and controllers of the body's immune defence system. Meditation has been found to modulate the expression of inflammatory cytokines in various diseases. For example, MBSR could prevent interleukin (IL)-10 downregulation in patients with fibromyalgia. ${ }^{21}$ Mindfulness practice is also linked to lower levels of IL- 6 and tumor necrosis factor- $\alpha($ TNF- $\alpha)$ in primary open-angle glaucoma patients. ${ }^{22}$ The regulation of MBSR on inflammatory cytokines in patients with breast cancer may be affected by disease stage and treatment strategies (surgery, radiation or chemotherapy). It has been noted that expression levels of TNF- $\alpha$ and IL- 6 reduced, while expression levels of interferon $\gamma(\mathrm{IFN}-\gamma)$ increased 
in patients diagnosed with early breast cancer after meditation. ${ }^{23}$ TNF- $\alpha$ and IL-6 levels appear to elevate during follow-up after meditation among survivors of breast cancer. ${ }^{24}$ There was no alteration in IL-6 levels after meditation in breast cancer patients with adjuvant chemotherapy and/or radiation therapy. ${ }^{25}$ Meditation can also monitor the immune system in normal individuals. Mindfulness intervention can diminish the level of C reactive protein in people with high inflammation (overweight or overstressed adults aged 45 years and over). ${ }^{26}$ Yoga combined with meditation allowed the immunity of people to be boosted, ${ }^{27}$ thereby enhancing both inflammatory cytokines and anti-inflammatory cytokines. In general, meditation helps inflammatory cytokines in vivo to maintain a fine-tuning balance, sometimes promoting inflammatory responses and sometimes suppressing excessive inflammatory responses.

\section{Insight into meditation and its epigenetics}

Long-term meditation modulates epigenetics and promotes health-related gene expression. Advanced mindfulness meditators display changes in histone modification and chromatin-regulated gene expression after meditation. ${ }^{28}$ The reduced expression of several histone deacetylase genes (HDAC 2, 3 and 9) and the altered overall modification of histones (H4ac and H3K4me3) is found in peripheral blood mononuclear cells. Meanwhile, the expression of the proinflammatory gene COX2, depending on the activity of deacetylated HDAC, is downregulated, which further explains the mechanisms of meditation in the treatment of major depressive disorder and inflammation-related diseases. Persistent MM also influences the epigenetic ageing rates (the level of deviation between the DNA methylation age and the chronological age).$^{29}$ The rate of epigenetic ageing significantly slows during meditation, thereby meditation has effects on anti-ageing. Additionally, long-term meditation exercises bring about consistent epigenetic responses in a broad range of genomic regions, ${ }^{30}$ most of which are bound up with neurological and mental illnesses, cardiovascular diseases and cancer. Some reports have indicated that patients with PTSD in veterans have decreases in FKBP5 intron 7 methylation after a mindfulness intervention. ${ }^{31}$ Although research on meditation methylation has been conducted, it is still in its infancy. Therefore, it is necessary that more investigations with more accurate tools and methods of data analysis are conducted to examine epigenetic regulation induced by meditation.

\section{Insight into meditation and its telomere biology}

Telomere length is an indicator of cell ageing and physiological stress, which gradually shortens during cell division and cell damages. Ornish $e t a l,{ }^{32}$ who first studied the relationship between meditation training and telomerase activity, has found that patients with prostate cancer exhibit higher telomerase activity after meditation. A few reports demonstrated that meditation practice was associated with increased telomerase activity in peripheral blood mononuclear cells. ${ }^{33}$ Several studies have also indicated that meditation intervention is related to an slight increase in telomere length ${ }^{34}$ or no change without shortening. ${ }^{35}$ In addition, meditation can also impact the expression of multiple telomere-related genes, ${ }^{36}$ especially producing more positive effects on telomere regulation in meditation training. ${ }^{37}$ Not only does telomere length increase, but also the expression of Gar1 and hnRNPA 1 (the gene encoding a protein that binds to telomerase RNA and DNA) elevate. To sum up, meditation training can improve telomere regulation, which ultimately contributes to health and ageing. However, the mechanisms of alterations in meditation remain to be further explored.

\section{APPLICATION OF MEDITATION IN MENTAL DISORDERS}

To date, meditation technology is gradually applied to the treatment and prevention of various mental illnesses. Particularly in major depressive disorders, it can be an alternative therapy of medication at the maintenance stage; meditation techniques may become an adjunctive treatment for patients with substance-related and addiction disorders as well as PTSD. However, the application of meditation techniques is still in its early stages in schizophrenia and attention deficit and hyperactivity disorders $(\mathrm{ADHD})$, and more research is required to further verify its efficacy.

\section{Major depressive disorders}

At present, meditation techniques have been extensively implemented for treating major depressive disorders, mainly MBIs and B-M techniques (embodying tai chi and yoga). Meditation is relatively efficacious in the acute and subacute phase of treatment of depressive disorders,${ }^{38}$ and our research also indicates that 8 weeks of MM effectively relieves depression and anxiety emotions and improves sleep quality. ${ }^{39}$ Meanwhile, meditation displays some adjunctive therapeutic effects on patients with severe major depressive disorder who are less effectively treated with antidepressant medication therapy. ${ }^{40}$ Furthermore, meditation also can be used in the prevention of depressive relapse. The report of patients with depressive disorder with three or more relapses conducted by the British Medical Research Council revealed that the recurrence rate can reduce from $78 \%$ to $36 \%$ by using MBCT. ${ }^{41}$ It can be further supported that the relapse rate $(44 \%)$ in the MBCT treatment group alone is equivalent to the relapse rate $(47 \%)$ in the antidepressant treatment group during maintenance therapy with 2 weeks of follow-up. ${ }^{42}$ Therefore, MBCT is expected to become an alternative therapy after discontinued maintenance of antidepressant drugs for treatment. Other studies demonstrated that the physical and mental techniques of meditation, encompassing tai chi, qi gong and yoga, can significantly alleviate depression and anxiety in patients with major depressive disorder, which is considered to become an effective complementary approach for the current 
mainstream drug therapy and psychotherapy. ${ }^{43}$ In brief, both the recent systematic review and meta-analysis ${ }^{38} 4344$ have further evaluated the remarkable feasibility and efficacy of meditation techniques in people with depressive disorders.

\section{Substance-related and addiction disorders}

Increasingly, meditation techniques are being applied to substance-related and addiction disorders, including alcohol use disorders, substance use disorders, tobacco use disorders, cannabis and stimulant use disorders, with the most commonly used techniques being MBRP and ACT. Mindfulness practice reduces the emotion distress, craving and withdrawal symptoms for nicotinedeprived smokers ${ }^{45}$ in combination with lower relapse in smoking cessation. ${ }^{46}$ ACT intervention decreases the craving behaviour of drug abusers ${ }^{47}$ as well as reuse of substance,${ }^{48}$ relieves pain in patients with chronic pain comorbid with opioid addiction and suppresses craving for opioids. ${ }^{49}$ Furthermore, MBRP eases the craving for alcohol in alcohol-dependent patients, alleviates anxiety and depression and improves quality of life.$^{50} \mathrm{In}$ addition, it displays improvements in emotional problems in adults with depression and anxiety along with remarkable decreases in the use of stimulants. ${ }^{51}$ Similarly, B-M technology can help young adults to regulate the management of emotion and decrease alcohol and drug abuse. ${ }^{52}$ In summary, meditation-based interventions show significant reductions in dependence, craving and other addiction-related symptoms by mitigating emotional states and mood imbalances.

\section{Post-traumatic stress disorder}

PTSD is a complicated and refractory mental illness that easily occurs after severe trauma. Neither medication nor trauma psychotherapy (cognitive processing therapy) can completely eliminate its symptoms. Meditation interventions may be an alternative therapy in the management of PTSD, including TM, sudarshan kriya yoga and MM as common techniques. It is apparent that meditation interventions yield positive effects on PTSD among veterans, ${ }^{53-55}$ which can alleviate intrusion and avoidance, modulate emotions and calm breathing. Moreover, MM can help reduce alcohol and drug abuse among veterans with PTSD. ${ }^{56}$ Next, MM may be an adjunctive treatment for adults with PTSD who experienced sexual abuse in childhood, with interventions yielding effects on PTSD symptom reduction and anxiety as well as depression relief. ${ }^{57}$ Other studies showed that TM also ameliorates the symptoms of PTSD and improves depressive emotions for college students in South Africa. ${ }^{58}$ Subsequently, it can be seen that meditation technology can help more patients with PTSD to get rid of pain and return to a normal life.

\section{Attention deficit and hyperactivity disorders}

Up to now, the efficacy of meditation intervention in adult patients diagnosed with ADHD is relatively manifest, prevailingly using MBIs. ${ }^{59}$ Mindfulness intervention can considerably improve attention in adults with ADHD, ${ }^{60-63}$ with additional improvements in executive functioning, ${ }^{63}$ working memory ${ }^{60}$ and anxiety and depressive emotions. ${ }^{61}$ Improved attention may be associated with increased activation of the left putamen, globus pallidus and thalamus. ${ }^{63}$ However, meditation interventions provide insufficient evidence in children and adolescents with ADHD and it is hard to identify its efficacy. ${ }^{64}$ Preliminary evidence shows that yoga and mindfulness interventions can decrease core symptoms of ADHD in children and adolescents ${ }^{65} 66$ and that joint participation in mindfulness-based interventions between parents and children with ADHD can help to relieve parental stress and over-reactivity. ${ }^{657}$ In conclusion, more high-quality randomised controlled trials are needed to substantiate the effectiveness of meditation interventions for children and adolescents with ADHD.

\section{Schizophrenia}

Meditation techniques have been tried for patients with schizophrenia over the years, with main techniques used being MBIs and ACT. Preliminary studies have suggested that MM can improve anger and aggression in acute patients with schizophrenia, schizoaffective disorder or bipolar disorder. ${ }^{68}$ It can also diminish symptoms of depression and anxiety in stabilised patients with chronic schizophrenia. ${ }^{69}$ In particular, it decreases pain and depressive emotions associated with auditory hallucinations ${ }^{70}$ and reduces the occurrence of various crisis situations. Furthermore, MM can relieve partial positive symptoms ${ }^{71} 72$ and negative symptoms ${ }^{69} 72$ of schizophrenia, enhance patients' awareness of their disease, shorten lengths of inpatient stay and reduce rehospitalisation rates. ${ }^{71} 72$ Our study exhibits that 8 months of meditation contributes to significant reductions in persistent hallucination and delusion symptoms of severe schizophrenic patients with more than a 20-year course. ${ }^{73}$ Although meditation interventions make initial progress in patients with schizophrenia, the evidence from these findings appears to not be sufficient, and randomised controlled trials in larger cohorts are warranted to further validate.

\section{CONCLUSIONS}

Over the past two decades, meditation has been used in a great variety of fields to relieve stress, regulate emotions and promote physical and mental health. In recent years, the application of meditation in the psychiatric field has gradually received attention. It has become an adjunctive and alternative therapy for depression, PTSD and ADHD and has been carried out for the acute and remission stages of treatment for severe schizophrenia. Additionally, it can ameliorate emotional distress, craving and withdrawal symptoms in substance addiction. However, the current researchers adopt different meditation methods and 
diverse training durations, which leads to the inability to systematically evaluate which type of meditation is more beneficial to which populations or diseases, and to completely elucidate the biological mechanism of meditation. In the future, further targets for selective meditation subtypes along with prescribed training time, and randomised controlled studies with sufficient samples are required to determine the efficacy of meditation on the one hand, and simultaneously study the mechanisms behind meditation on the mind-body interaction, which can better display the positive function of meditation as an ancient physical and mental healing method in promoting human health.

\section{Contributors HS wrote the paper; MJC and DHC read and edited the manuscript.}

Funding This study was funded by the following fundings : Shanghai Jiao Tong University Medical and Engineering Joint Grant (YG2016ZD06), Shanghai Jiao Tong University Joint Art and Science Funding (14JCRZ05), National Natural Science Foundation of China (81671336), National Key R\&D Program of China (2017YFC0909200)

\section{Competing interests None declared.}

Patient consent for publication Not required.

Provenance and peer review Not commissioned; externally peer reviewed.

Data availability statement The data that support the findings of this study are available from the corresponding authors on reasonable request.

Open access This is an open access article distributed in accordance with the Creative Commons Attribution Non Commercial (CC BY-NC 4.0) license, which permits others to distribute, remix, adapt, build upon this work non-commercially, and license their derivative works on different terms, provided the original work is properly cited, appropriate credit is given, any changes made indicated, and the use is non-commercial. See: http://creativecommons.org/licenses/by-nc/4.0/.

\section{REFERENCES}

1 Lutz A, Slagter HA, Dunne JD, et al. Attention regulation and monitoring in meditation. Trends Cogn Sci 2008;12:163-9.

2 Ainsworth B, Eddershaw R, Meron D, et al. The effect of focused attention and open monitoring meditation on attention network function in healthy volunteers. Psychiatry Res 2013;210:1226-31.

3 Chiesa A, Malinowski P. Mindfulness-based approaches: are they all the same? J Clin Psychol 2011;67:404-24.

4 Xiao L, JF L. The discussions on the definition of Tai Chi[C]. Proceedings of the 6th Member Congress and Academic Annual Meeting of the Chinese Medical Qigong Society. Proceedings of the 6th Member Congress and Academic Annual Meeting of the Chinese Medical Qigong Society, China, 2019:381-4.

5 Travis F, Shear J. Focused attention, open monitoring and automatic self-transcending: categories to organize meditations from Vedic, Buddhist and Chinese traditions. Conscious Cogn 2010;19:1110-8.

6 Zeng X, Chiu CPK, Wang R, et al. The effect of loving-kindness meditation on positive emotions: a meta-analytic review. Front Psychol 2015;6:93-4.

7 Fox KCR, Nijeboer S, Dixon ML, et al. Is meditation associated with altered brain structure? A systematic review and metaanalysis of morphometric neuroimaging in meditation practitioners. Neuroscience \& Biobehavioral Reviews 2014;43-73. [Epub ahead of print: Online First: Epub Date].

8 Yang C-C, Barrós-Loscertales A, Li M, et al. Alterations in brain structure and amplitude of low-frequency after 8 weeks of mindfulness meditation training in Meditation-Naïve subjects. Sci Rep 2019;9. [Epub ahead of print: Online First: Epub Date].

9 Engen HG, Bernhardt BC, Skottnik L, et al. Structural changes in socio-affective networks: multi-modal MRI findings in longterm meditation practitioners. Neuropsychologia 2018;116-33. doi:10.1016/j.neuropsychologia.2017.08.024. [Epub ahead of print: Online First: Epub Date]

10 Hernández SE, Barros-Loscertales A, Xiao Y, et al. Gray matter and functional connectivity in anterior cingulate cortex are associated with the state of mental silence during Sahaja yoga meditation. Neuroscience 2018;371-406. doi:10.1016/j. neuroscience.2017.12.017. [Epub ahead of print: Online First: Epub Date].

11 Sperduti M, Martinelli P, Piolino P. A neurocognitive model of meditation based on activation likelihood estimation (ale) meta-analysis. Conscious Cogn 2012;21-276. doi:10.1016/j. concog.2011.09.019. [Epub ahead of print: Online First: Epub Date].

12 Hernández SE, Suero J, Rubia K, et al. Monitoring the neural activity of the state of mental silence while practicing Sahaja yoga meditation. J Altern Complement Med 2015;21-179. doi:10.1089/ acm.2013.0450. [Epub ahead of print: Online First: Epub Date].

13 Ziegler DA, Simon AJ, Gallen CL, et al. Closed-Loop digital meditation improves sustained attention in young adults. Nat Hum Behav 2019;3-757. doi:10.1038/s41562-019-0611-9. [Epub ahead of print: Online First: Epub Date]

14 Berkovich-Ohana A, Glicksohn J, Ben-Soussan TD, et al. Creativity is enhanced by long-term mindfulness training and is negatively correlated with trait Default-Mode-Related Low-Gamma InterHemispheric connectivity. Mindfulness 2017;8-727. doi:10.1007/ s12671-016-0649-y. [Epub ahead of print: Online First: Epub Date].

15 Garrison KA, Zeffiro TA, Scheinost D, et al. Meditation leads to reduced default mode network activity beyond an active task. Cogn Affect Behav Neurosci 2015;15-720. doi:10.3758/s13415-015-03583. [Epub ahead of print: Online First: Epub Date].

16 Simon R, EngstrÃ $\mid m$ M. The default mode network as a biomarker for monitoring the therapeutic effects of meditation. Front Psychol 2015;06. doi:10.3389/fpsyg.2015.00776. [Epub ahead of print: Online First: Epub Date]

17 Jiang $\mathrm{H}, \mathrm{He} \mathrm{B}$, Guo X, et al. Brain-Heart interactions underlying traditional Tibetan Buddhist meditation. Cereb Cortex 2019;36. [Epub ahead of print: Online First: Epub Date].

18 Reyes del Paso GA, Langewitz W, Mulder LJM, et al. The utility of low frequency heart rate variability as an index of sympathetic cardiac tone: a review with emphasis on a reanalysis of previous studies. Psychophysiology 2013;50-487. doi:10.1111/psyp.12027. [Epub ahead of print: Online First: Epub Date].

19 Critchley HD, Eccles J, Garfinkel SN. Interaction between cognition, emotion, and the autonomic nervous system 2013:59-77.

20 Lumma AL, Kok BE, Singer T. Corrigendum: "Is meditation always relaxing? Investigating heart rate, heart rate variability, experienced effort and likeability during training of three types of meditation". Int. J. Psychophysiol;117:38-45. (S0167876015001658)(10.1016/j. ijpsycho.2015.04.017). International Journal of Psychophysiology 2017;117:126-30 10.1016/j.ijpsycho.2017.02.014[published Online First: Epub Date]

21 Andrés-Rodríguez L, Borràs X, Feliu-Soler A, et al. ImmuneInflammatory pathways and clinical changes in fibromyalgia patients treated with Mindfulness-Based stress reduction (MBSR): a randomized, controlled clinical trial. Brain Behav Immun 2019;80-119. doi:10.1016/j.bbi.2019.02.030. [Epub ahead of print: Online First: Epub Date]

22 Dada T, Mittal D, Mohanty K, et al. Mindfulness meditation reduces intraocular pressure, lowers stress biomarkers and modulates gene expression in glaucoma: a randomized controlled trial. J Glaucoma 2018;27-1067. doi:10.1097/IJG.0000000000001088. [Epub ahead of print: Online First: Epub Date]

23 Witek Janusek L, Tell D, Mathews HL. Mindfulness based stress reduction provides psychological benefit and restores immune function of women newly diagnosed with breast cancer: a randomized trial with active control. Brain Behav Immun 2019;80-373. doi:10.1016/j.bbi.2019.04.012. [Epub ahead of print: Online First: Epub Date].

24 Reich RR, Lengacher CA, Klein TW, et al. A Randomized Controlled Trial of the Effects of Mindfulness-Based Stress Reduction (MBSR[BC]) on Levels of Inflammatory Biomarkers Among Recovering Breast Cancer Survivors. Biol Res Nurs 2017;19-464. doi:10.1177/1099800417707268. [Epub ahead of print: Online First: Epub Date]

25 Kenne Sarenmalm E, Mårtensson LB, Andersson BA, et al. Mindfulness and its efficacy for psychological and biological responses in women with breast cancer. Cancer Med 2017;6-1122. doi:10.1002/cam4.1052. [Epub ahead of print: Online First: Epub Date].

26 Villalba DK, Lindsay EK, Marsland AL, et al. Mindfulness training and systemic low-grade inflammation in stressed community adults: evidence from two randomized controlled trials. PLoS One 2019;14. doi:10.1371/journal.pone.0219120. [Epub ahead of print: Online First: Epub Date]

27 Cahn BR, Goodman MS, Peterson CT, et al. Yoga, meditation and Mind-body health: increased BDNF, cortisol awakening response, and altered inflammatory marker expression after a 3-month yoga 
and meditation retreat. Front Hum Neurosci 2017;11. doi:10.3389/ fnhum.2017.00315. [Epub ahead of print: Online First: Epub Date].

28 Kaliman P, Álvarez-López MJ, Cosín-Tomás M, et al. Rapid changes in histone deacetylases and inflammatory gene expression in expert meditators. Psychoneuroendocrinology 2014;40-107. doi:10.1016/j. psyneuen.2013.11.004. [Epub ahead of print: Online First: Epub Date].

29 Chaix R, Alvarez-López MJ, Fagny M, et al. Epigenetic clock analysis in long-term meditators. Psychoneuroendocrinology 2017;85-214. doi:10.1016/j.psyneuen.2017.08.016. [Epub ahead of print: Online First: Epub Date].

30 García-Campayo J, Puebla-Guedea M, Labarga A, et al. Epigenetic response to mindfulness in peripheral blood leukocytes involves genes linked to common human diseases. Mindfulness 2018;9-1159. doi:10.1007/s12671-017-0851-6. [Epub ahead of print: Online First: Epub Date]

31 Bishop JR, Lee AM, Mills LJ, et al. Methylation of FKBP5 and SLC6A4 in Relation to Treatment Response to Mindfulness Based Stress Reduction for Posttraumatic Stress Disorder. Front Psychiatry 2018;9. doi:10.3389/fpsyt.2018.00418. [Epub ahead of print: Online First: Epub Date].

32 Ornish D, Lin J, Chan JM, et al. Effect of comprehensive lifestyle changes on telomerase activity and telomere length in men with biopsy-proven low-risk prostate cancer: 5-year follow-up of a descriptive pilot study. Lancet Oncol 2013;14-1120. doi:10.1016/ S1470-2045(13)70366-8. [Epub ahead of print: Online First: Epub Date].

33 Jacobs TL, Epel ES, Lin J, et al. Intensive meditation training, immune cell telomerase activity, and psychological mediators. Psychoneuroendocrinology 2011;36-681. doi:10.1016/j. psyneuen.2010.09.010. [Epub ahead of print: Online First: Epub Date].

34 Tolahunase M, Sagar R, Dada R. Impact of yoga and meditation on cellular aging in apparently healthy individuals: a prospective, openlabel single-arm exploratory study. Oxid Med Cell Longev 2017;2017. [Epub ahead of print: Online First: Epub Date].

35 Carlson LE, Beattie TL, Giese-Davis J, et al. Mindfulness-based cancer recovery and supportive-expressive therapy maintain telomere length relative to controls in distressed breast cancer survivors. Cancer 2015;121-484. doi:10.1002/cncr.29063. [Epub ahead of print: Online First: Epub Date].

36 Epel ES, Puterman E, Lin J, et al. Meditation and vacation effects have an impact on disease-associated molecular phenotypes. Trans/ Psychiatry 2016;6. doi:10.1038/tp.2016.164. [Epub ahead of print: Online First: Epub Date].

37 Conklin QA, King BG, Zanesco AP, et al. Insight meditation and telomere biology: the effects of intensive retreat and the Moderating role of personality. Brain Behav Immun 2018;70-245. doi:10.1016/j.bbi.2018.03.003. [Epub ahead of print: Online First: Epub Date].

38 Jain FA, Walsh RN, Eisendrath SJ, et al. Critical analysis of the efficacy of meditation therapies for acute and subacute phase treatment of depressive disorders: a systematic review. Psychosomatics 2015;56-152. doi:10.1016/j.psym.2014.10.007. [Epub ahead of print: Online First: Epub Date].

39 Xue T, Li H, Wang M-T, et al. Mindfulness meditation improves metabolic profiles in healthy and depressive participants. CNS Neurosci Ther 2018;24-574. doi:10.1111/cns.12816. [Epub ahead of print: Online First: Epub Date].

40 Sharma A, Barrett MS, Cucchiara AJ, et al. A Breathing-Based meditation intervention for patients with major depressive disorder following inadequate response to antidepressants. J Clin Psychiatry 2017;78-63. doi:10.4088/JCP.16m10819. [Epub ahead of print: Online First: Epub Date]

$41 \mathrm{SH}$ M, Teasdale JD. Mindfulness-based cognitive therapy for depression: replication and exploration of differential relapse prevention effects. J Consult Clin Psychol 2004;72-40. [Epub ahead of print: Online First: Epub Date].

42 Kuyken W, Hayes R, Barrett B, et al. Effectiveness and costeffectiveness of mindfulness-based cognitive therapy compared with maintenance antidepressant treatment in the prevention of depressive relapse or recurrence (prevent): a randomised controlled trial. The Lancet 2015;386-73. doi:10.1016/S0140-6736(14)62222-4. [Epub ahead of print: Online First: Epub Date].

43 Zou L, Yeung A, Li C, et al. Effects of Meditative movements on major depressive disorder: a systematic review and meta-analysis of randomized controlled trials. J Clin Med 2018;7. doi:10.3390/ jcm7080195. [Epub ahead of print: 01 Aug 2018].

44 Zhang Z, Zhang L, Zhang G, et al. The effect of CBT and its modifications for relapse prevention in major depressive disorder: a systematic review and meta-analysis. BMC Psychiatry 2018;18. doi:10.1186/s12888-018-1610-5. [Epub ahead of print: Online First: Epub Date].

45 Luberto CM, McLeish AC. The effects of a brief mindfulness exercise on state mindfulness and affective outcomes among adult daily smokers. Addict Behav 2018;77-80. doi:10.1016/j. addbeh.2017.09.013. [Epub ahead of print: Online First: Epub Date].

46 Oikonomou MT, Arvanitis M, Sokolove RL. Mindfulness training for smoking cessation: a meta-analysis of randomized-controlled trials. $J$ Health Psychol 2017;22-1850. doi:10.1177/1359105316637667. [Epub ahead of print: Online First: Epub Date].

47 Shorey RC, Elmquist J, Gawrysiak MJ, et al. A randomized controlled trial of a mindfulness and acceptance group therapy for residential substance use patients. Subst Use Misuse 2017;52-1410. doi:10.10 80/10826084.2017.1284232. [Epub ahead of print: Online First: Epub Date].

48 Lee EB, An W, Levin ME, et al. An initial meta-analysis of acceptance and commitment therapy for treating substance use disorders. Drug Alcohol Depend 2015;155-7. doi:10.1016/j.drugalcdep.2015.08.004. [Epub ahead of print: Online First: Epub Date].

49 Smallwood RF, Potter JS, Robin DA. Neurophysiological mechanisms in acceptance and commitment therapy in opioid-addicted patients with chronic pain. Psychiatry Res Neuroimaging 2016;250-14. doi:10.1016/j.pscychresns.2016.03.001. [Epub ahead of print: Online First: Epub Date]

50 von Hammerstein C, Khazaal Y, Dupuis M, et al. Feasibility, acceptability and preliminary outcomes of a mindfulnessbased relapse prevention program in a naturalistic setting among treatment-seeking patients with alcohol use disorder: a prospective observational study. BMJ Open 2019;9. doi:10.1136/ bmjopen-2018-026839. [Epub ahead of print: Online First: Epub Date].

51 Glasner-Edwards S, Mooney L, Ang A, et al. Mindfulness based relapse prevention improves stimulant use among adults with major depression and generalized anxiety disorder. Drug Alcohol Depend 2015;156. doi:10.1016/j.drugalcdep.2015.07.1135. [Epub ahead of print: Online First: Epub Date]

52 Park C, Russell B, Fendrich M. Mind-Body approaches to prevention and intervention for alcohol and other drug use/abuse in young adults. Medicines 2018;5. doi:10.3390/medicines5030064. [Epub ahead of print: Online First: Epub Date]

53 Nidich S, Mills PJ, Rainforth M, et al. Non-trauma-focused meditation versus exposure therapy in veterans with post-traumatic stress disorder: a randomised controlled trial. Lancet Psychiatry 2018;5-986. doi:10.1016/S2215-0366(18)30384-5. [Epub ahead of print: Online First: Epub Date]

54 Mathersul DC, Tang JS, Schulz-Heik RJ, et al. Study protocol for a non-inferiority randomised controlled trial of sky breathing meditation versus cognitive processing therapy for PTSD among Veterans. BMJ Open 2019;9. doi:10.1136/bmjopen-2018-027150. [Epub ahead of print: Online First: Epub Date].

55 Seppälä EM, Nitschke JB, Tudorascu DL, et al. Breathing-based meditation decreases posttraumatic stress disorder symptoms in U.S. military veterans: a randomized controlled longitudinal study. $J$ Trauma Stress 2014;27-405. doi:10.1002/jts.21936. [Epub ahead of print: Online First: Epub Date].

56 Davies RL, Prince MA, Bravo AJ, et al. Moral injury, substance use, and posttraumatic stress disorder symptoms among military personnel: an examination of trait mindfulness as a Moderator. $J$ Trauma Stress 2019;32-423. doi:10.1002/jts.22403. [Epub ahead of print: Online First: Epub Date].

57 Earley MD, Chesney MA, Frye J, et al. Mindfulness intervention for child abuse survivors: a 2.5-year follow-up. J Clin Psychol 2014;70-941. doi:10.1002/jclp.22102. [Epub ahead of print: Online First: Epub Date].

58 Bandy CL, Dillbeck MC, Sezibera V, et al. Reduction of PTSD in South African university students using transcendental meditation practice. Psychol Rep 2020;123-740.

doi:10.1177/0033294119828036. [Epub ahead of print: Online First: Epub Date].

59 Poissant $\mathrm{H}$, Mendrek A, Talbot N, et al. Behavioral and cognitive impacts of Mindfulness-Based interventions on adults with attentiondeficit hyperactivity disorder: a systematic review. Behav Neurol 2019;2019-16. doi:10.1155/2019/5682050. [Epub ahead of print: Online First: Epub Date].

60 Bachmann K, Lam AP, Sörös P, et al. Effects of mindfulness and psychoeducation on working memory in adult ADHD: a randomised, controlled fMRI study. Behav Res Ther 2018;106-56. doi:10.1016/j.brat.2018.05.002. [Epub ahead of print: Online First: Epub Date]

61 Gu Y, Xu G, Zhu Y. A randomized controlled trial of MindfulnessBased cognitive therapy for college students with ADHD. J Atten 
Disord 2018;22-399. doi:10.1177/1087054716686183. [Epub ahead of print: Online First: Epub Date].

62 Hepark S, Janssen L, de Vries A, et al. The efficacy of adapted MBCT on core symptoms and executive functioning in adults with ADHD: a preliminary randomized controlled trial. J Atten Disord 2019;23-362. doi:10.1177/1087054715613587. [Epub ahead of print: Online First: Epub Date].

63 Janssen L, Kan CC, Carpentier PJ, et al. Mindfulness-based cognitive therapy V. treatment as usual in adults with ADHD: a multicentre, single-blind, randomised controlled trial. Psychol Med 2019;49-65. doi:10.1017/S0033291718000429. [Epub ahead of print: Online First: Epub Date].

64 Zhang J, Díaz-Román A, Cortese S. Meditation-based therapies for attention-deficit/hyperactivity disorder in children, adolescents and adults: a systematic review and meta-analysis. Evid Based Ment Health 2018;21-94. doi:10.1136/ebmental-2018-300015. [Epub ahead of print: Online First: Epub Date].

65 Lo HHM WSWL, Wong JYH, et al. The effects of family-based mindfulness intervention on ADHD Symptomology in young children and their parents: a randomized control trial. Journal of attention disorders 2017. [Epub ahead of print: Online First: Epub Date].

66 Hariprasad VR, Arasappa R, Varambally S, et al. Feasibility and efficacy of yoga as an add-on intervention in attention deficithyperactivity disorder: an exploratory study. Indian J Psychiatry 2013;55-84. [Epub ahead of print: Online First: Epub Date].

67 Gershy N, Meehan KB, Omer H, et al. Randomized clinical trial of mindfulness skills augmentation in parent training. Child Youth Care Forum 2017;46-803. doi:10.1007/s10566-017-9411-4. [Epub ahead of print: Online First: Epub Date].
68 Mistler LA, Ben-Zeev D, Carpenter-Song E, et al. Mobile mindfulness intervention on an acute psychiatric unit: feasibility and acceptability study. JMIR Ment Health 2017;4. doi:10.2196/mental.7717. [Epub ahead of print: Online First: Epub Date].

69 Tabak NT, Horan WP, Green MF. Mindfulness in schizophrenia: associations with self-reported motivation, emotion regulation, dysfunctional attitudes, and negative symptoms. Schizophr Res 2015;168-542. doi:10.1016/j.schres.2015.07.030. [Epub ahead of print: Online First: Epub Date].

70 Louise S, Rossell SL, Thomas N. The acceptability, feasibility and potential outcomes of an individual Mindfulness-Based intervention for hearing voices. Behav Cogn Psychother 2019;47-216. doi:10.1017/S1352465818000425. [Epub ahead of print: Online First: Epub Date].

71 Chien WT, Thompson DR. Effects of a mindfulness-based psychoeducation programme for Chinese patients with schizophrenia: 2-year follow-up. Br J Psychiatry 2014;205-59. doi:10.1192/bjp.bp.113.134635. [Epub ahead of print: Online First: Epub Date].

72 Chien WT, Bressington D, Yip A, et al. An international multi-site, randomized controlled trial of a mindfulness-based psychoeducation group programme for people with schizophrenia. Psychol Med 2017:47-2096. doi:10.1017/S0033291717000526. [Epub ahead of print: Online First: Epub Date].

73 Sheng J-L, Yan Y, Yang X-H, et al. The effects of Mindfulness Meditation on hallucination and delusion in severe schizophrenia patients with more than 20 years' medical history. CNS Neurosci Ther 2019;25-150. doi:10.1111/cns.13067. [Epub ahead of print: Online First: Epub Date].

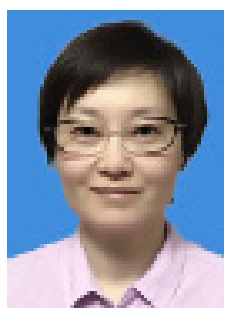

Hui Shen obtained her bachelor's degree in clinical medicine at the Shanghai Second Medical University in Shanghai, China, in 2003. In the same year she began working at the Shanghai Mental Health Center (SMHC). Currently, she is the chief rehabilitation doctor at SMHC. Her main research interests include the treatment of schizophrenia and bipolar disorder, and the cognitive function and rehabilitation therapy for psychiatric patients. 